\title{
AC 2009-628: ENHANCEMENT OF WRITTEN COMMUNICATION ON STRUCTURAL SYSTEMS USING CALIBRATED PEER REVIEW
}

\section{Anne Nichols, Texas A\&M University}

Dr. Nichols is an Assistant Professor of Architecture at Texas A\&M University. She teaches structural analysis, design, and planning at the undergraduate and graduate level. She is a civil engineer with research interests in the structural mechanics and modeling of masonry and cement materials. 


\title{
Enhancement of Written Communication on Structural Systems Using Calibrated Peer Review
}

\begin{abstract}
Calibrated Peer Review (CPR $\left.{ }^{\mathrm{TM}}\right)$ is a web-based software tool for incorporating writing assignments in courses that are not typically writing intensive. The goal is for students to write and critique the work of their peers on technical topics by learning to calibrate writing samples and anonymously reviewing a subset of their classmates writing assignments, freeing the instructor from the time consuming task of grading every student's work.

This tool was used for two terms in a required architectural structural systems course in the Master of Architecture graduate program at Texas A\&M University. The intended student learning outcomes were improved written communication of structural knowledge on assessments, particularly essay exam questions, and in a term report on an architectural building case study conducted by a team. The tool was not intended to impart content, although that did occur, but to give the students directed practice in self-assessing and assessing the effectiveness of the written communication of their peers using a narrowly focused set of criteria for quality and quantity. In addition, the students were required to edit their reviewed texts based on the peer review comments and complete another round of peer reviews.

This paper will present the analysis of the scored data for the CPR ${ }^{\mathrm{TM}}$ assignments, which includes the student calibration competency, self and peer reviewing competency. The correlation of the student competencies to their performance on written exam questions and quality of the term reports will be quantified. The effectiveness of the tool will be evaluated with respect to the performance of prior classes having used the tool on a trial basis and prior classes that did not use the tool.
\end{abstract}

\section{Introduction}

Graduates of accredited programs of Architecture by the National Architecture Accrediting Board (NAAB) ${ }^{1}$ are expected to be able to demonstrate writing and speaking skills, design skills, technical documentation skills, and the understanding and appropriate application of structural and environmental systems technology, amongst other performance criteria. Design students focus most of their effort on graphical presentation skills which are regularly reviewed and critiqued, with cursory attention paid to formal writing and speaking skills, which are not. They have no formal technical writing training, yet, professional architects are expected to prepare formal proposals and reports, and communicate with consulting engineers.

In the only required course on structural systems and planning in one such program, two learning objectives identify the relationship of the course subject matter to the effective communication and demonstration of the understanding of structural systems and behavior required for good planning: 
...The student will be able to evaluate their own skills, or lack thereof, with respect to reading and comprehension of structural concepts, clarity of written communication, reasonable determination of precision in numerical data, and accuracy of computations.

...The student will be able to articulate the physical phenomena, behavior and design criteria which influence structural space and form. (depth)... The student will draw upon existing organizational and communication skills to clearly present concepts and personal interpretation of structural knowledge in writing assignments and examinations (clarity, precision, accuracy, relevance, depth, breadth, logic, significance).

The demonstration of technical writing and speaking skills was through written assignments, essays on examinations, a term report produced by a team, and a presentation of the report by the team. The mechanism for feedback commonly consisted of written marks or grades on the assessments by the instructor or grader, all but for three exercises that generated peer review only.

Software or web-based tools to facilitate peer based writing have been initiated at universities (e.g. PRAZE at the University of Melbourne ${ }^{2}$ ) and for use within internet-based course development packages (e.g. Waypoint Outcomes ${ }^{3}$ with Moodle ${ }^{4}$.) Other applications can automate the grading of writing assignments for traits, spelling, and grammar based on an instructor's rubric without peer involvement (e.g. Intelligent Essay Assessor ${ }^{5}$ ). Through the Molecular Science Project supported by the National Science Foundation at the University of California, a calibrated peer review system was developed to involve peer collaboration, writing, critical thinking, and tutorials with visualizations of molecules, processes, and systems. The Howard Hughes Medical Institute is currently funding the development of the software known as Calibrated Peer Review (CPR) ${ }^{6}$.

Calibrated Peer Review is useful for technology courses as a tool for incorporating writing assignments in non-writing-based courses using a blind peer review process, rather than a single, well trained evaluator. The students receive indirect training through an assessment of their evaluation skills with writing samples that are considered poor, average, and good. The evaluation covers both content (subject matter) and style (clarity of communication).

This method of peer evaluation is similar to the process used in design studios which exposes students to quality work by the reviews of individual projects in a design studio or across studios. The culture of critique, praise, and criticism "teaches" the students to appreciate and strive for quality. The availability of a tool to expose students to quality technical writing (and poor quality writing) by the peers of graduate students in architecture could provide some familiarity and comfort to learning a subject considered difficult and foreign.

The initial goal of using such a tool was to improve the quality of student technical writing on the term project report, and to expose the students to acceptable use of referenced material and scrutiny for possible plagiarism ${ }^{7}$. The study of the use of CPR with subject-specific writing assignments in one term compared to two previous and one subsequent term without the tool did not show a statistical effect on the term project report grades, although the instructor satisfaction was higher. The students showed better competence at rating their peers' work but consistently 
had inflated self-ratings. The value to the student of the assignment was indirectly correlated to the grade received. The first exercise was scored, but full credit was given for completing the assignment. The credit for the second, however, was based on overall score; so the lower the grade, the higher the dissatisfaction and resentment by the students that they were made to write, review, and be reviewed.

With consideration of the results of the first application of CPR, the goal with the next use of the tool was to focus on quality communication of content for improved performance on exam essay questions and on the term project report.

\section{Calibrated Peer Review}

Calibrated Peer Review (CPR) is used by a large number of institutions in a variety of classes, but has found widespread use in large survey courses in the sciences, english, and psychology. The process involves the submission of writing for an assignment that has an organized list of assignment goals, source materials to be used, specific instructions, and guiding questions. After submission, the student must complete reviews of a high quality calibration essay, a mid quality calibration essay, and a low quality calibration essay. All calibration essays have the same set of questions for the students to answer and be scored by with tailored keys. The students also rate the work with an integer scale (1 to 10 as high) which is compared to the text rate key.

The student is issued a reviewer competency index (RCI) from 1-6 (low to high) as a result of their scoring and deviation from the keyed text rating. Ratings above 4 mean the reviewer is reasonably proficient. Default scoring challenge levels are provided in the software tool, but custom scoring challenge levels can be created. After "mastering" the calibrations, the student blindly reviews and rates three works of their peers using the same questions and criteria as the calibrations, although the text rate for each student work is not predetermined. The text rate is determined by an averaging calculation based on the text rating given by each reviewer weighted with the square of a factor corresponding to the reviewer's competency index.

The student's overall score comprises their proficiency on each calibration, their ratings with respect to deviation limits for each peer review they performed and gave to themselves, and the average rating of their text by the reviewers.

\section{Implementation}

With the trial use of CPR in a term, the intent was for the students to become familiar with the software program using two of the topic areas- masonry arches and membrane structures (air inflated, air supported, tensile nets and shells) - by using structural terminology to communicate their understanding of the systems and planning issues. The recommended use, based on experience with large survey courses, was to make the first assignment "low risk" by giving credit for completing it, and to make subsequent assignments have increasingly higher credit weights based on program generated scores. ${ }^{8}$ The design students, however, after receiving their overall score on the credit assignment, were offended that their peers had reviewed them instead of the instructor; and moreover, believed that content should have been the only basis for the 
grade. The importance of style for clear communication as the vehicle to deliver content, which was repeatedly stressed, was not well heeded or highly valued.

After two terms without CPR, the tool was reintroduced as an exercise within weekly practice assignments that included calculation problems, concept or calculation problems in the form of licensing examination multiple choice questions, and short answer problems. The CPR assignments required describing the solution of a computational problem and presenting the analysis so that viewers could read and understand it. The submission to CPR was due at or near the time the entire assignment was due, with the calibrations and peer review performed after this deadline. A total of three CPR assignments were spaced between mid-term and final exams throughout the term as shown in Figure 1. Each exam had an essay question worth $20 \%$ of the exam total, and the exams accounted for half of the course grade. The first CPR assignment allowed a week for the calibration and peer review to be completed, whereas the subsequent ones had $21 / 2$ days and 2 days to complete, respectively.

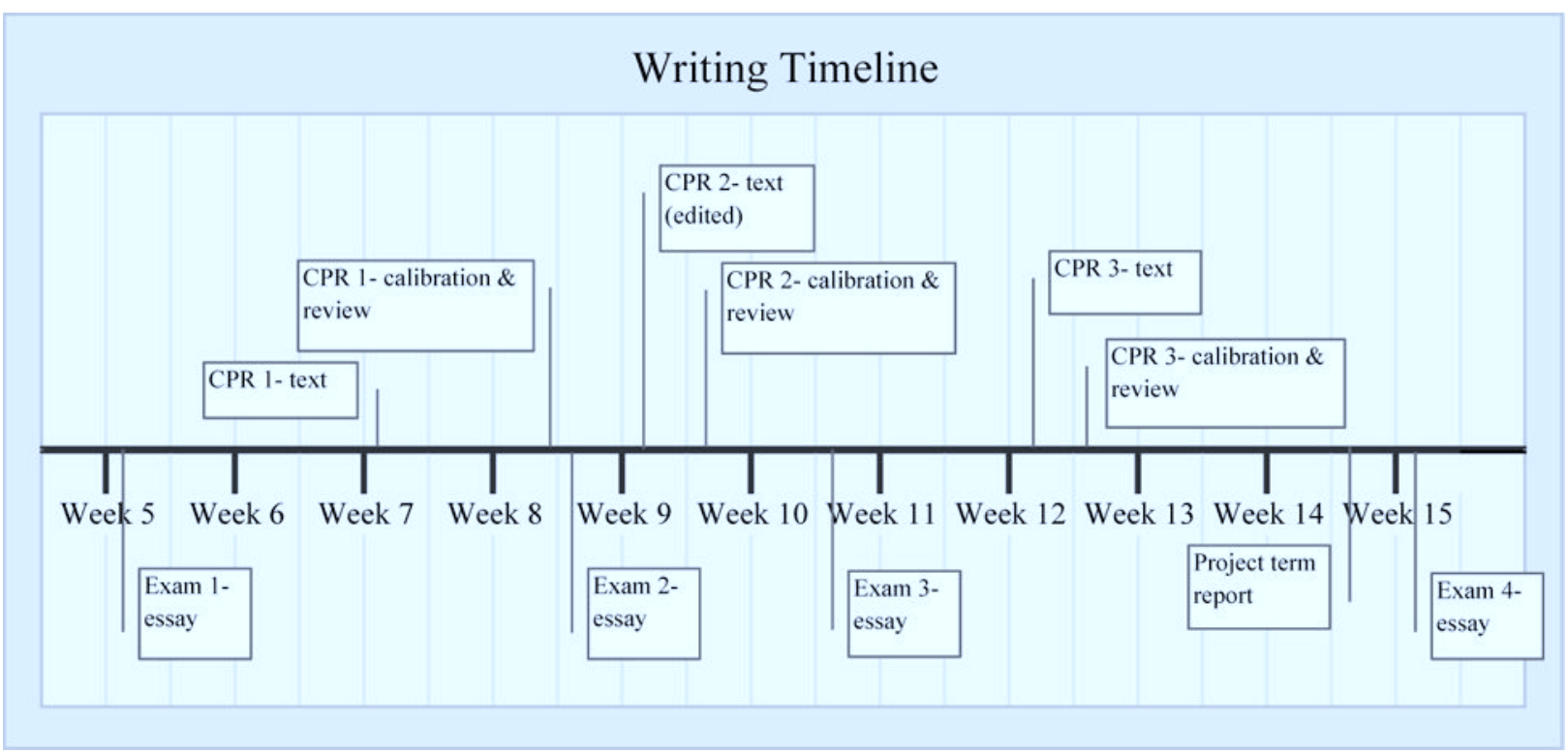

Figure 1. Writing Timeline

The CPR assignments were designed similarly to introductory physics assignments available from the Institutional Library of the software. Those assignments typically asked for ordered calculations with respect to changing variable quantities, and for an analysis or thoughtful comparison based on the results. Rather than create new assignment questions, the CPR assignments were directly tied to computational problems and asked for the student to clearly explain their solution process in writing. Half of the question credit was given for providing the worked solution with half given for the CPR submission and reviews. Credit was not weighted by the overall score calculated by CPR.

The CPR tool requires text to be in simple html format, so the inclusion of readable equations and calculations had to be articulated careful. The writer can select to see a preview of the input text to verify the final format the reviewer will see. 
The first CPR assignment corresponded to the material on two way plate analysis and design as shown in Figure 2.

5. Calibrated Peer Review Question Solve the following problem and clearly explain your process in writing. It must be submitted to CPR (http://cpr.tamu.edu/).

A $18 \times 24-\mathrm{ft}$ two way interior bay flat slab supports a live loading of $50 \mathrm{lb} / \mathrm{ft}^{2}$ and has a dead load of $120 \mathrm{lb} / \mathrm{ft}^{2}$. All columns are 24 in. square (reducing the longer side clear span, but not the strip widths). Determine all the design moments. Use an ultimate strength design approach (combined loads) $\underline{\text { based on ASCE-7 }}$ (Note Set 3.2).

Partial Answer: $w=224 \mathrm{lb} / \mathrm{ft}^{2}$, $M_{U_{T}}\left(M_{o}\right)=243,936 \mathrm{lb}-\mathrm{ft}$ column strip $m-=13,213^{\mathrm{lb}-\mathrm{ft} / \mathrm{ft}}$ or $13,280^{\mathrm{lb}-\mathrm{ft} / \mathrm{ft}}$ middle strip $m+=3,795^{\mathrm{lb}-\mathrm{ft} / \mathrm{tt}}$

$\{+$ column $m+$, middle strip $m-\}$

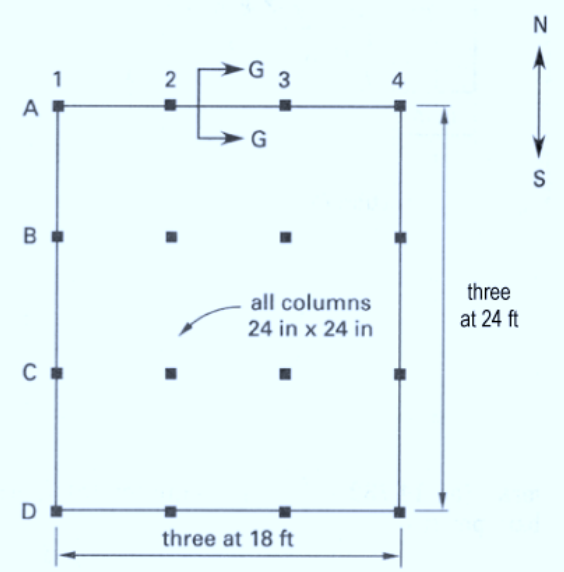

Figure 2. First CPR Assigment Statement

The students had exposure to the textbook interpretation of the strip method and the interpretation of the direct design method and design coefficients of ACI $318^{9}$ for two-way slabs, as hinted by the combination of answers and symbols provided in the partial answers. So there was a possibility of variation in the solutions to be communicated. The text entry was due in the time period between mid-term exams, after the experience of the first exam with an essay question which also was structured with an organized list of requirements with multiple paths to demonstrate understanding as illustrated in Figure 3.

Part 3) Worth 20\%

Compose a response to the following series of questions with no more than $2 / 3$ of a page of text. The content will be graded in terms of the accuracy, completeness, and relevance of the ideas expressed. The form will be evaluated for clarity, organization, correct spelling and grammar, and legibility. Content will have higher worth than form. Poor format will likely result in unrecognizable content.

24. Air-inflated membranes, air-supported membranes, nets, and shell structures are structural types which resist forces and stresses primarily in the surface or thickness of the shape. Choose two from these four structural types and make a sketch with a label of each. Describe the similarities and the differences in design requirements for strength (type and direction) and serviceability with respect to the overall shaping and usual loading being supported for the types chosen. Identify the problems with large concentrated forces and with lateral loads for each structural type chosen

Figure 3. Example Exam 1 Essay Question

The guiding questions the students were provided are shown in Figure 4, and a sample text entry (which did not carefully use simple html for superscripts) is shown in Figure 5. 


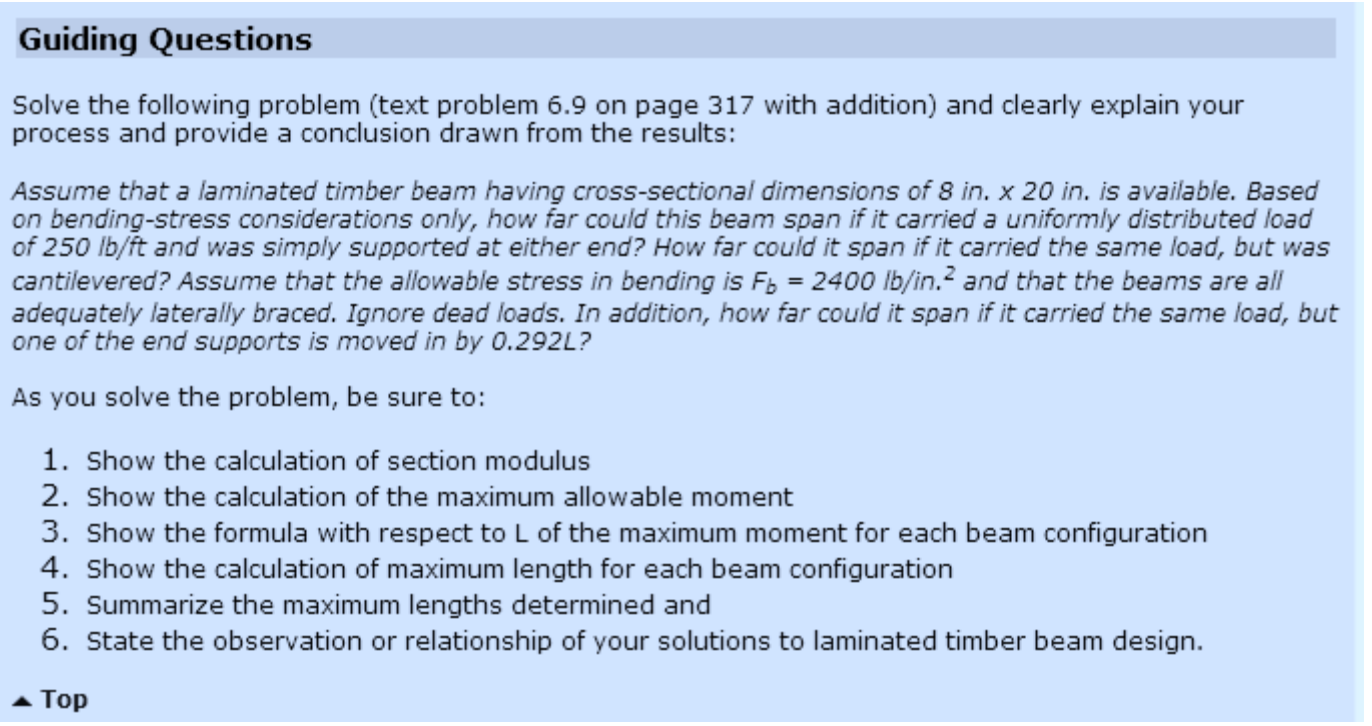

Figure 4. First CPR Assignment Guiding Questions

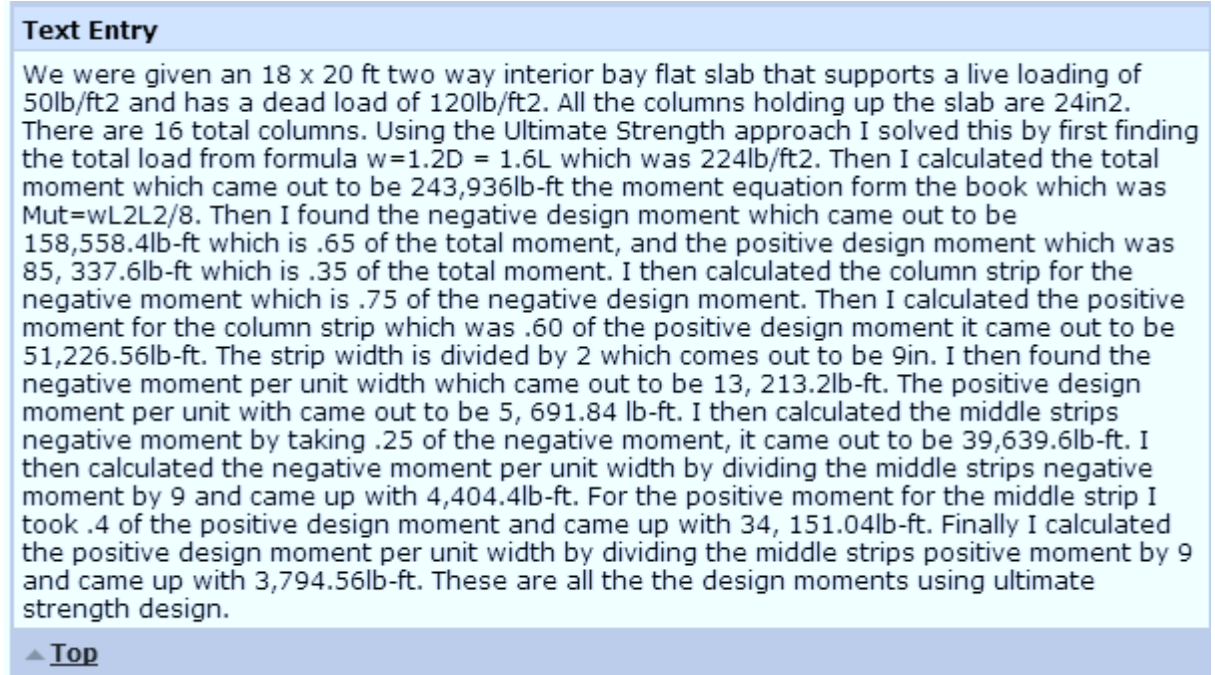

Figure 5. First CPR Assignment Text Entry Example

The second CPR assignment required the students to submit the edited text of the first CPR assignment one week after the reviews were completed. The students had to view the reviews of their work, which included the text rating and the mandatory reviewer comments like that shown for a different student in Figure 6, and incorporate the feedback into the edited text. 


\begin{tabular}{|c|c|c|c|c|}
\hline \multicolumn{5}{|l|}{ Reviews You Performed } \\
\hline Answer Key & \multicolumn{3}{|c|}{ Max. Allowable Dev. $=3.0$} & \\
\hline Reviews & \multicolumn{2}{|c|}{$\begin{array}{c}\text { Rating } \\
\text { Deviation }\end{array}$} & \multicolumn{2}{|c|}{$\begin{array}{l}\text { Overall } \\
\text { Grade }\end{array}$} \\
\hline Review 1 & \multicolumn{2}{|c|}{0.32} & \multicolumn{2}{|c|}{ Mastered } \\
\hline Review 2 & \multicolumn{2}{|c|}{1.92} & \multicolumn{2}{|c|}{ Mastered } \\
\hline Review 3 & \multicolumn{2}{|c|}{0.96} & \multicolumn{2}{|c|}{ Mastered } \\
\hline \multicolumn{5}{|l|}{ Reviews Performed of Your Work } \\
\hline Answer Key & & & & $\begin{array}{l}\text { Max. Allowable } \\
\text { Deviation }=2 / 3\end{array}$ \\
\hline \multirow{2}{*}{ Questions } & \multicolumn{4}{|c|}{ Answers } \\
\hline & Review 1 & Review 2 & Review 3 & Self-Assessment \\
\hline $\begin{array}{l}\text { 1. Did the essay show the load factors of } 1.2 \text { for dead } \\
\text { load and } 1.6 \text { for live load? }\end{array}$ & Yes & Yes & Yes & Yes \\
\hline $\begin{array}{l}\text { 2. Did the design load calculation for } w_{u} \text { correctly multiply } \\
\text { and add the factored loads? } A=Y e s, B=N_{0}, C=\text { The } \\
\text { answer has part of this. }\end{array}$ & A & A & A & A \\
\hline $\begin{array}{l}\text { 3. Did the essay properly determine the critical span } \\
\text { length } \mathrm{I}_{\mathrm{n}} \text { and } \mathrm{I}_{2} \text { of } 22 \mathrm{ft} \text { and } 18 \mathrm{ft} \text { ? }\end{array}$ & $\underline{\text { No }}$ & $\underline{\text { No }}$ & $\underline{\text { No }}$ & Yes \\
\hline $\begin{array}{l}\text { 4. Did the essay properly identify where the span is } \\
\text { located and the support conditions? } A=Y e s, B=N o \text {, } \\
C=\text { The answer has part of this. }\end{array}$ & $\mathrm{C}$ & $\mathrm{B}$ & B & $\mathrm{C}$ \\
\hline $\begin{array}{l}\text { 5. Did the essay indicate the use of the correct moment } \\
\text { coefficients with the total design moment } \mathrm{M}_{0} \text { ? }\end{array}$ & No & No & No & Yes \\
\hline $\begin{array}{l}\text { 6. Did the essay properly change the strip moments into } \\
\text { moments per unit width? } A=Y e s, B=\text { No, C=No, but the } \\
\text { answer was consistent with previous errors. }\end{array}$ & B & B & B & A \\
\hline $\begin{array}{l}\text { 7. Did the essay summarize the solution in words? } \\
A=Y e s, B=N_{0}, C=\text { The answer has part of this. }\end{array}$ & B & A & $\underline{\mathrm{B}}$ & A \\
\hline $\begin{array}{l}\text { 8. Are there misspellings, grammatical errors or } \\
\text { typographical errors in the text? }\end{array}$ & Some (1 or 2$)$ & Some (1 or 2$)$ & None & None \\
\hline 9. Was the solution presented in an orderly fashion? & $\underline{\text { No }}$ & $\underline{\text { Yes }}$ & $\underline{\text { No }}$ & Yes \\
\hline 10. How would you rate this text? & $\underline{8}$ & $\underline{6}$ & $\underline{4}$ & 10 \\
\hline Weight Applied to Ratings & 0.85 & 1.00 & 1.00 & \\
\hline \multicolumn{5}{|l|}{ Weighted Average Text Rating } \\
\hline \multicolumn{5}{|l|}{ Scores and Overall Grade } \\
\hline Stage & Performan & & & Score \\
\hline Text Entry & Weighted Text R & $=5.80$ & & $9 x y+$ of 20 \\
\hline Calibrations & Calibration De/1 & $=4.67$ & & 0 out onse \\
\hline Reviews & g. Review D fuiat & 1.07 & & 0 out of 30 \\
\hline Self-Assessment & Assessm $/$ nt Dev & $=4.20$ & & out of 20 \\
\hline Overall Score & & & & out of 100 \\
\hline & $\begin{array}{l}\text { Peer Re } \\
\text { Question: } \\
\text { Answer: } 6 \\
\text { Explanatior } \\
\text { answers. It } \\
\text { with the cor } \\
\text { correctly. }\end{array}$ & $\begin{array}{l}\text { ew 2, R } \\
\text { would you r } \\
\text { le incorrect } \\
\text {, however, } \\
\text { approach, I }\end{array}$ & $\begin{array}{l}\text { gu } \mathbf{Q u} \\
\text { is text? } \\
\text { ach was } \\
\text { e the stu }\end{array}$ & $\begin{array}{l}\text { tion } \\
\text { en which led to incorrect } \\
\text { anding of the problem and } \\
\text { would have solved it }\end{array}$ \\
\hline
\end{tabular}

Figure 6. Student Results Example and Reviewer Comment

An example of the revised text for Figure 5 is shown in Figure 7. 


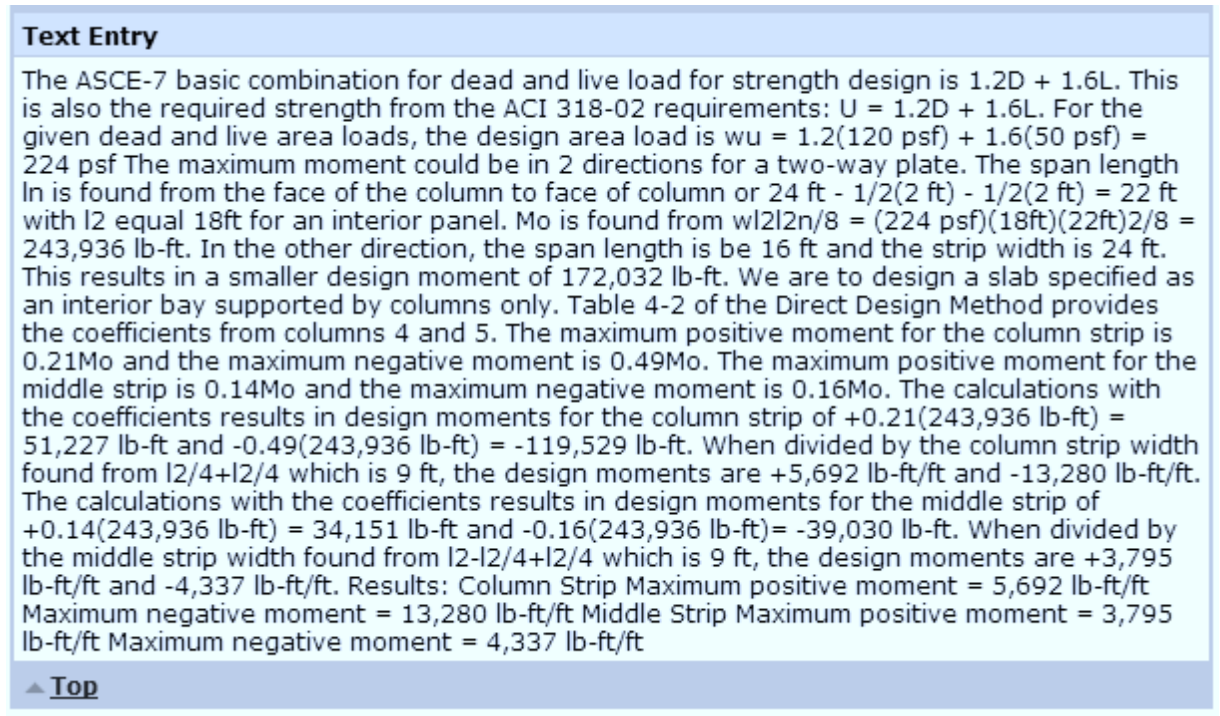

Figure 7. Edited CPR Assignment Text Entry Example

The final CPR assignment and reviews were due between the last mid term and the end of the term over the material on timber design (Figure 8). The additional assignment was provided to continue the emphasis on quality communication rather than rote analysis, and reinforce the skills practiced. The writing did not have a required response to the reviewer comments, but slightly over half the students did view the comments. A sample text entry is shown in Figure 9.

5. Calibrated Peer Review Question: Solve the following problem (text problem 6.9 on page 317 with addition) and clearly explain your process in writing and provide a conclusion drawn from the results. It must be submitted to CPR (http://cpr.tamu.edu/).

6.9 Assume that a laminated timber beam having cross-sectional dimensions of $8 \mathrm{in} . \times 20 \mathrm{in}$. is available. Based on bending-stress considerations only, how far could this beam span if it carried a uniformly distributed load of $250 \mathrm{lb} / \mathrm{ft}$ and was simply supported at either end? How far could it span if it carried the same load, but was cantilevered? Assume that the allowable stress in bending is $F_{b}=2400 \mathrm{lb} /$ in. $^{2}$ and that the beams are all adequately laterally braced. Ignore dead loads. In addition, how far could it span if it carried the same load, but one of the end supports is moved in by 0.292L? (See Section 6.4.1) Answer: $58.4 \mathrm{ft}$ if simply supported.

Figure 8. Final CPR Assigment Statement 


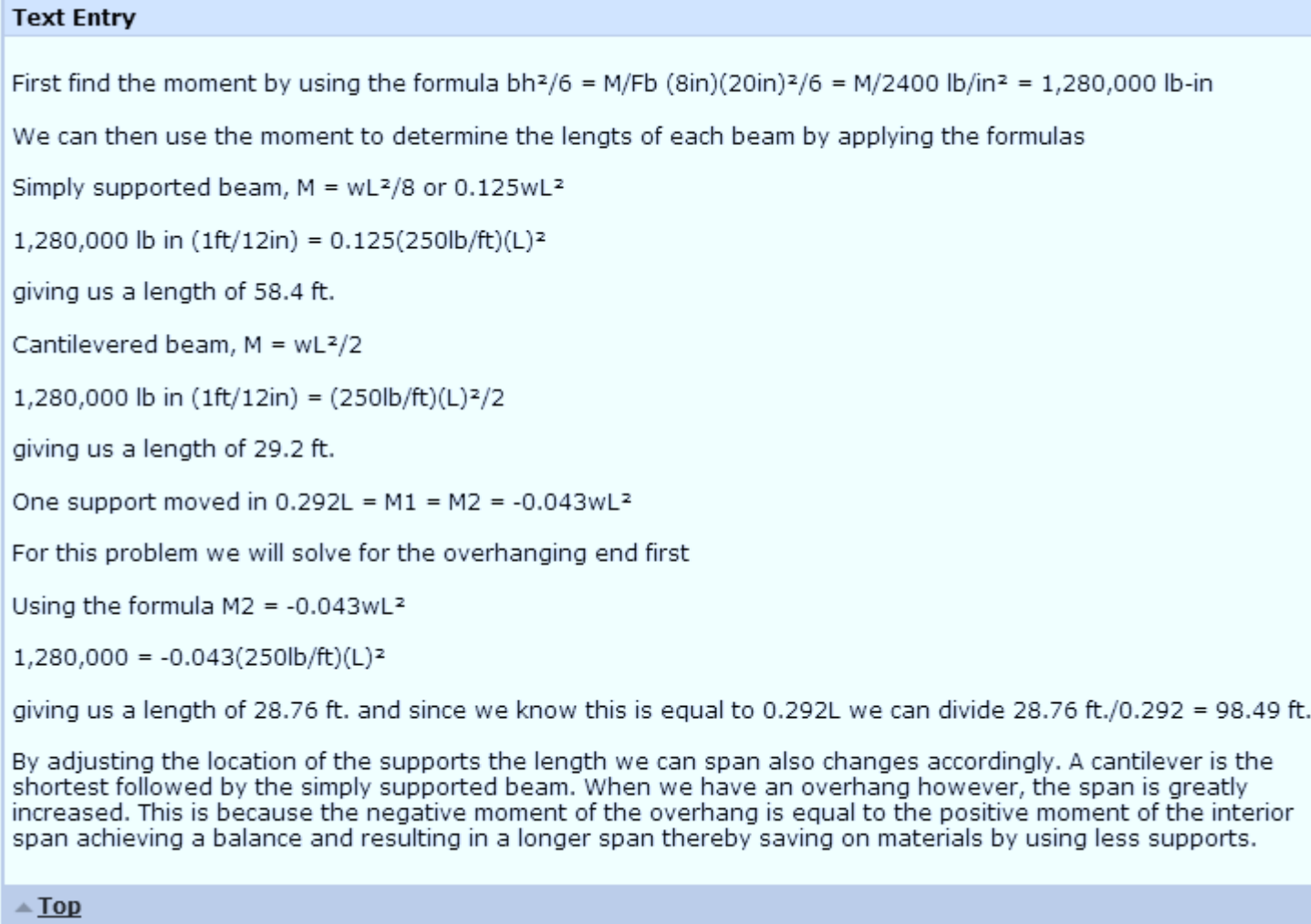

Figure 9. Final CPR Assignment Text Entry Example

The last experience with an essay question was after this CPR assignment. The exam was over the material on steel design, masonry design, foundation design and structural supervision in relation to all the course content. The essay question is presented in Figure 10 with an example student response. 
Part 3) Worth $20 \%$

Compose a response to the following series of questions with no more than $2 / 3$ of a page of text. The content will be graded in terms of the accuracy, completeness, and relevance of the ideas expressed. The form will be evaluated for clarity, organization, correct spelling and grammar, and legibility. Content will have higher worth than form. Poor format will likely result in unrecognizable content.

24. You are designing a forty story office structure with a height about $500 \mathrm{ft}(160 \mathrm{~m})$ and a width about $85 \mathrm{ft}(30 \mathrm{~m})$ that is situated within a moderate earthquake zone. The soil is a highly compressible clay with bedrock at $100 \mathrm{ft}(30 \mathrm{~m})$ below grade.

Identify the basic design and planning issues with respect to strength, stiffness, serviceability and stability for this building. This should include identification of loads (general sizes, kind and direction), suitability of building type or framing, building behavior under loads, and foundation requirements.

Choose a structural system for this building and identify how the vertical layout, horizontal layout, and interconnectedness will address the issues identified. Also choose a foundation system and identify how it will address the issues identified.

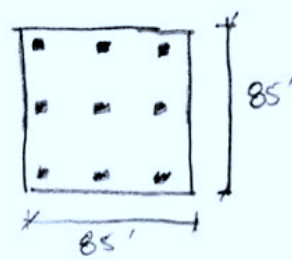

SOME OF THE ISSUES CONCERNING THE STRENGTH, STIFFNESS, SERVICEABILITY + STABILITY OF THIS STRUCTURE STEM FROM TWO THINGS: ITS SLENDER (500 FT TALL BY 85 FT SOUARE IN PLAN) AND IT IS BEING BUILT IN AN EARTHOUAKE ZONE. THE LATERAL LOADS ARE THE MAIN CONCERNS HERE. YOU WANT
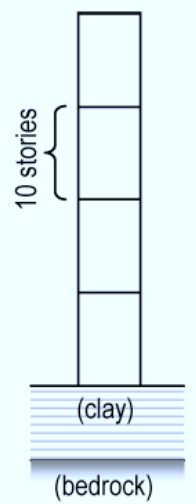

elevation at scale A FRAMING SYSTEMS THAT IS FLEXIBLE ENOUGH TO HANDLE EARTHOUAKES + STRONG WINDS, BUT NOT TOO INCREDIBLY FLEXIBLE THAT THE OCCUPANTS OF THE BUILDING BECOME UNCOMFORTABLE OR SICK. THE FOUNDATION WILL PLAY A VITAL ROLL IN STABILITY IN THIS STRUCTURE UNDER THESE HEAVY LATERAL LOADS. THE TOWER WILL DEFLECT AT AN EXPONENTIAL RATE THE FURTHER UP YOU GET. ANOTHER DEVICE THAT MIGHT WANT TO BE TAKEN ADVANTAGE OF ARE TUNED WIGHTS OR SLOSH TANKS TO OFFSET THE LATERAL LOADS AND PROVIDE MORE MASS AT THE TOP OF THE TOWER TO LIMIT HORIZONTAL DEFLECTION.

FOR THIS BUILDING I WOULD CHOOSE A STEEL STRUCTURAL SYSTEM WITH A PILE FOUNDATION STRETCHING THE 100 FT TO THE SOLID BEDROCK. THE BAY SIZE IN PLAN WILL BE 28' X 28' WITH COLUMN 28' O.C. THE BAY SIZE IN ELEVATION WILL BE 28' X 12.5' WITH THE FLOOR TO FLOOR HEIGHT BEING 12.5'. ASSUME NO LARGE FLOOR OPENINGS, AND TYPICAL FLOOR CONFIGURATIONS ALL THE WAY UP THE TOWER. I WOULD SPECIFY K-BRACING WITH W-SECTIONS BETWEEN FLOORS. THE CONNECTIONS WILL BE PINNED (BOLTED). THIS WILL ALLOW THE BUILDING TO FLEX UNDER EARTHQUAKES + HIGH WINDS. THE PILES IN THE FOUNDATION WILL GO STRAIGHT DOWN TO THE SOILI LAYER OF STRATA, EXCEPT FOR ON THE ENDS - THEY WILL SPLAY OUTWARD TO PREVENT OVERTURNING

Figure 10. Example Exam 4 Essay Question and Response

All CPR assignments were assigned the default low difficult scoring level, which required the student to correctly answer $50 \%$ of two specified style questions and $50 \%$ of seven specified content questions while not deviating by more than 3 points from the calibration text rating to master a calibration and receive 10 points. The student could not deviate by more than 3 points from the weighted average text rating to master a review of a peer's writing and receive 10 points. To receive all 20 points for assessing their own work (self assessment), the student could not deviated by more than 2 points from the weighted average text rating. They could receive 10 points if they deviated more than 2 points, but less than 3 points, from the weighted average text rating. They also received twice the value of the average weighted text rating of 10 or less for up to 20 points. 


\section{Performance Measures}

The reviewer competency indexes (RCI) were examined for the three assignments, and showed that the majority of the students were proficient, having indexes of 4, 5 and 6. Only for the first CPR assignment were there students with lower indexes. The weighting factor assigned to the RCI levels can be seen in the Student Results Example (Figure 6). The indexes determined with the three assignments were not statistically different as determined by the Student's t-test using a $95 \%$ confidence level of similarity for two sample sets assuming unequal variances.

The weighted text ratings were examined for the three assignments. The data analysis indicates that there is a statistical difference between text rating of the edited assignment and the first (unedited) assignment and between the edited assignment and the final assignment, while there is no statistical difference between the first (unedited) assignment and the final assignment. There was a slight increase in the number of high RCI levels with the second assignment, which didn't change for the third assignment, so the difference to the weighted text ratings could be from the familiarity with the repeated subject material.

The relationship between the reviewer competency index and the averaged text rating was also examined to see if a strong calibrator and reviewer could possibly be a strong communicator.

Figure 11 shows the distribution of average text rating to the RCI level. The median text rating did not show a consistent increase by RCI level, but the edited assignment did show an elevation of the average text ratings and a reduction of the distribution from the mean.

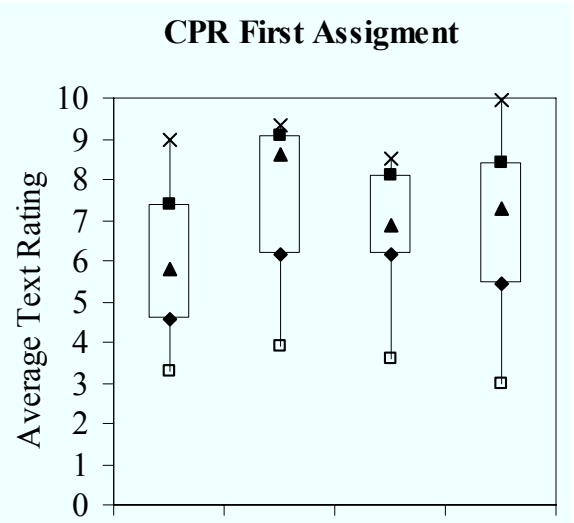

RCI-2 RCI-4 RCI-5 RCI-6
CPR Edited Assigment

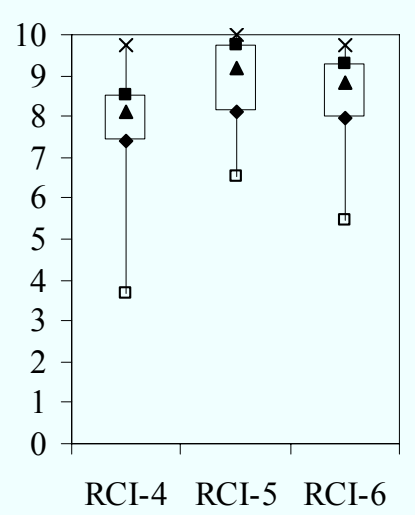

CPR Final Assigment

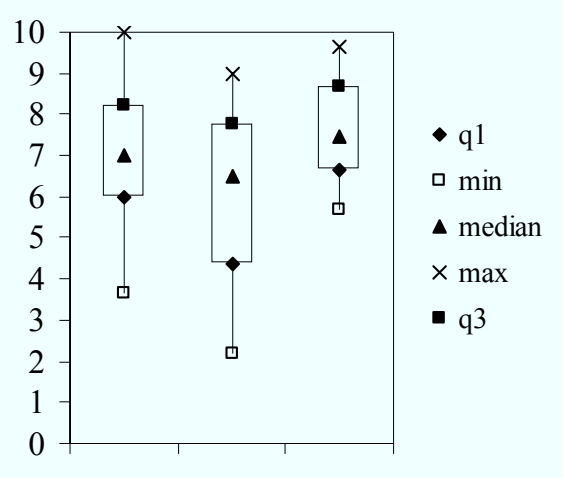

Figure 11. Distribution of Text Rating by Reviewer Competancy Index (RCI) (2 low, 6 high)

The self assessment scores, which are a measure of how close the self rating is to the average text rating, were examined for the three assignments. The data analysis indicates that there is a statistical difference between the self assessment scores of the final assignment and the first (unedited) assignment and between the final assignment and the edited assignment, while there is no statistical difference between the first (unedited) assignment and the edited assignment. It appears to indicate that the students were not as critical of their own work at the end of the term 
with the rush to complete final design reviews and term project reports, as the average self assessment deviations increased for the majority of students.

The overall scores generated by the software based on the calibrations, peer reviews, and average text rating, were also examined for the three assignments. The distribution by assignment is presented in Figure 12. The data analysis indicates that there is a statistical difference between the overall scores of the edited assignment and the final assignment, while there is no statistical difference between the first (unedited) assignment and the edited assignment and between the first (unedited) assignment and the final assignment. The RCI was not statistically different between the edited and final assignment, while the average text ratings and self assessment scores were statistically different. The average text ratings and the self assessment scores, on average, decreased from the edited to final assignments, which may indicate an inattention to quality writing at that point in the term.

Distribution of Overall Score

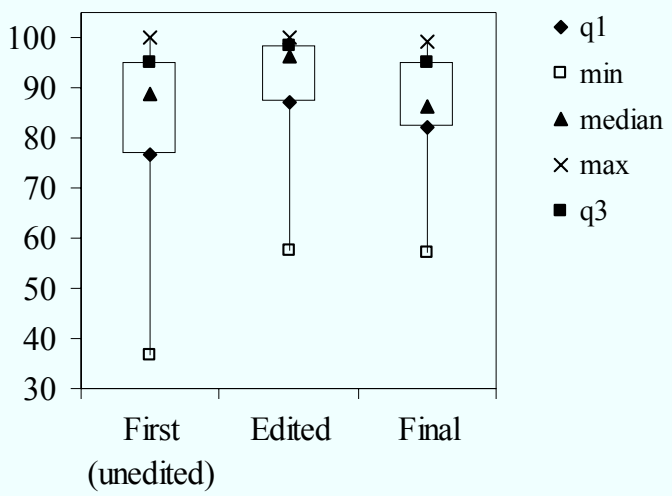

Figure 12. Distribution of Overall Scores by Assignment

\section{Analysis}

As the quality of the text increased, as indicated by the average text rating and overall scores in the edited assignment, and then regressed in the last assignment, the timing of the assignments and the relationship to the other written assessments was investigated. The average percentage of credit for the essay exam questions on each exam showed steady improvement with an increase in score and decrease in standard deviation, as shown by the average and distribution bars in Figure 13. The score averages were compared for the top half of the scores to the bottom half of the scores each exam, and also showed good correlation of increase by exam, with the bottom half increasing the score averages at a greater rate with a nearly constant standard deviation. 


\section{Exam Essay Score Averages}

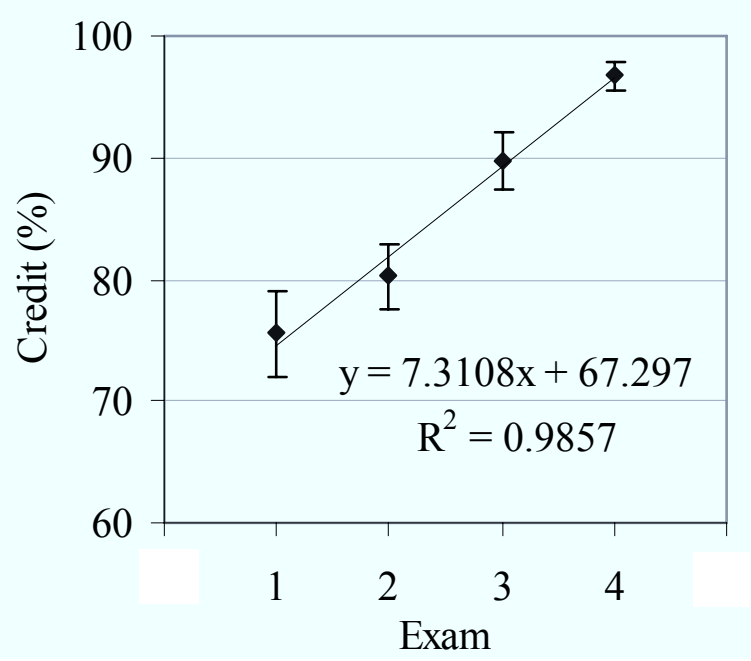

Figure 13. Essay Score Averages by Exam

The trial use of CPR for a term used two assignments. The comparison of the overall scores for the trial assignments and the three from the next implementation are shown in Figure 14. The RCI and self assessment scores were not statistically different for the two assignments in the trial term, and the change in overall scores and distribution was slight. The application in the next term does seem to indicate that the reading, writing, and assessing skills of the students in the first assignment was wide spread, and the subsequent writing assignments brought the students skills closer to alignment with each other for consistently better writing each exam.

Distribution of Overall Score by Term

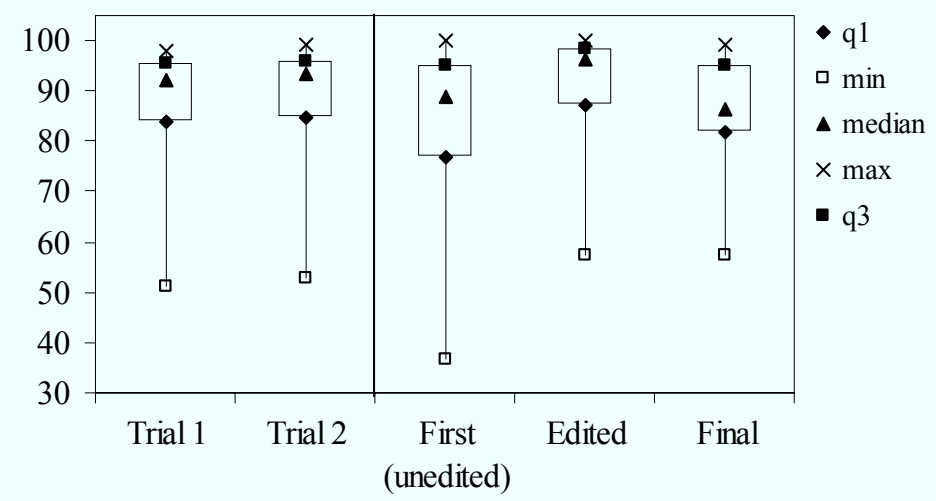

Figure 14. Distribution of Overall Scores by Term

The other major writing assignment used consistently in five terms was the term project report created by project teams of a building case study. The indirect influence from the CPR assignments on the writing skills of the primary authors and the editing skills of the team members reviewing the work was examined based on project score. The rubric for grading the term project reports (Table 1) was made available to all but the first of the five terms. $30 \%$ of the credit was given for style and organization. 


\begin{tabular}{|c|c|}
\hline & $\begin{array}{c}\text { Possible } \\
\text { Points }\end{array}$ \\
\hline Clarity of Presentation & 15 \\
\hline $\begin{array}{l}\text { Organization } \\
\text { Introduction } \\
\text { Background } \\
\text { Body } \\
\text { Conclusion }\end{array}$ & 15 \\
\hline $\begin{array}{l}\text { Thoroughness of Evaluation } \\
\text { Sufficient identification evidence } \\
\text { Description of main structural system } \\
\text { Identification of components } \\
\text { Connection description } \\
\text { Lateral resisting system description } \\
\text { Description of Loads } \\
\text { Load transfer path } \\
\text { Lateral loading behavior } \\
\text { Foundation and soil description }\end{array}$ & 45 \\
\hline Attention to Components and Systems & 10 \\
\hline $\begin{array}{l}\text { Sufficient Technical Data Provided } \\
\text { Modeling } \\
\text { Analysis of Results }\end{array}$ & 15 \\
\hline
\end{tabular}

Table 1. Term Project Report Evaluation Rubric

The term project report was worth $20 \%$ of the term grade in all but the first term when it was worth $10 \%$ and the remaining credit was given to weekly assignments.

Figure 15 shows the overall performance of the terms by term grade to average report score. The trial use of CPR for separate assignments was in Term 3. Term 5 is the one with three CPR exercises within the regular weekly assignments. 


\section{Term Grade and Report Performance}

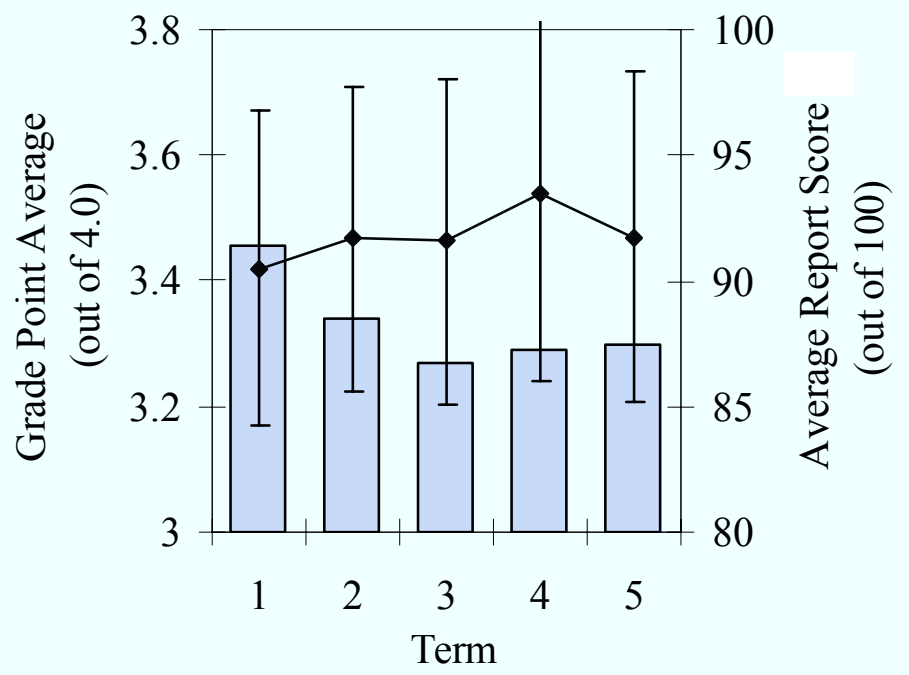

Grade Point Average

$\longrightarrow$ Average Report Score with Standard Deviation

Figure 15. Term and Project Report Grades

There is a positive trend in average report scores, but a decrease in grade point average of the first term using CPR (3). The report scores for term 1 and 4 were statistically different by the Student's t-test analysis (95\% confidence level) with term 4 occurring between the terms using CPR. There was no statistical difference between the report scores of any other terms. The average exam scores for terms 3, 4, and 5, which used the same format by including essay questions, were also not statistically different.

It is worth noting that the term project report is submitted at the end of the term when the full effort for design reviews occurs, and may be seeing the same lack of attention as the final CPR assignment which had lower text ratings and overall scores than the first (unedited) and edited assignments.

\section{Conclusions}

The use of the Calibrated Peer Review assignments does not appear to produce any dramatic increase in student performance. The editing assignment did show improvement in average text ratings and overall scores, but the improvement did not continue through the final assignment when editing was not required. The students with below average writing skills appear to get the greatest benefit. With the three CPR assignments, $60 \%$ of the students improved average text ratings only when forced to edit and $20 \%$ improved with each assignment. The biggest impact of the writing exercises appears to be in the quality of essay writing for term exams, for which the highly motivated students have 15 to 20 minutes to compose, edit and review themselves.

There was a limited amount of feedback from the students in the formal course evaluations on the writing assignments with the current implementation, while there was a great deal of 
feedback with the trial use. There was mention that the exercises were very valuable to some students, but the students dissatisfied with the mandatory nature of the course and subject material included in their lists that the exercises were a waste of time because the course subject was not composition.

While CPR results include the required reviewer comments for all assignments, the scoring system does not allow for direct comparison with an original and edited text, and there is no numerical determination that the edited text addressed the shortcomings of the reviewers based on reviewer competency indices.

It does appear that a methodical, regular application of writing in a technically oriented subject is beneficial for higher level thinking and analysis, and can limit the interpretation by students that they are being given "English assignments". Requiring self editing may always be necessary for graduate students, however. In an ideal setting, the peer review of the term project reports using CPR could provide the critique and editing direction in order to improve the final documents, but the simple html format does not support figures and graphic images easily.

\section{Summary}

The web-based tool, Calibrated Peer Review, for including writing assignments within technically-based courses like structural systems, was used to improve communication skills for graduate students in Architecture who have no formal training in technical writing. The tool provided exposure for students to levels of quality writing, and empowered them to critique and be critiqued in an environment similar to studio project design reviews. The trial use of CPR was motivated by the disparity between the quality of presentation graphics and written reports for a term project. The results indicated that there was some improvement in term project report grades, but the tool was not well accepted by the students for isolated assignments.

The implementation of written assignments using CPR was modified following a term without CPR assignments. In this term, the students were required to submit a written solution for computational problems assigned in two weekly assignments and provide a summary and conclusion. In addition, the submission for the first assignment was required to be edited and resubmitted based on reviewer comments. The timing of the assignments was distributed between other regular writing assessments of exam essays and term project reports.

The software generates results for the assignments based on a reviewer competency index (RCI) determined by the mastery of calibration reviews including style and content, and review text rating. In addition, the quality of the text through the average text rating and the accuracy with the self-assessment rating contribute to the overall assignment score. The RCI values, weighted text ratings, and self assessment scores for the three assignments were analyzed, and indicated that the students remained at the same competency level through the three assignments, and that the weighted text ratings and self assessing improved with the editing assignment, but regressed with the last assignment late in the term. The writing and critiquing practice had some effect on the quality and scoring of essays in exam distributed through the term, but that the term project report quality may have suffered from the same end-of-term distractions as the final CPR assignment. 
Calibrated Peer Review is an extremely efficient tool to incorporate writing assignments when the course content and expression of knowledge does not traditionally emphasize communication skills. It evaluates key skills of critiquing for readers and writers. While the performance results are not dramatic, it does indicate that regular use of communication skills necessary to the success of practicing professionals through assessments that are framed by the objective that all communication enhances learning through critique of self work and peer work is valuable.

\section{Bibliography}

1. The National Accrediting Board, NAAB Conditions for Accreditation For Professional Degree Programs in Architecture, 2004 edition, Washington, DC.

2. Mulder, R.A. \& Pearce, J.M. (2007). PRAZE: innovating teaching through online peer review. In ICT:

Providing choices for learners and learning. Proceedings ascilite Singapore 2007. http://www.ascilite.org.au/conferences/singapore07/procs/mulder.pdf

3. Subjective Metrics, Inc., Waypoint ${ }^{\top M}$ Outcomes, www.gowaypoint.com (2009)

4. Moodle ${ }^{\mathrm{TM}}$ (GNU Public License), http://moodle.org (2009)

5. Pearson Education, Inc., Intelligent Essay Assessor ${ }^{\mathrm{TM}}$, www.knowledge-technologies.com/prodIEA.shtml (2009)

6. University of California Los Angeles, Calibrated Peer Review, http://cpr.molsci.ucla.edu/ (2001).

7. Nichols, A.B., "Using Calibrated Peer Review as a Teaching Tool for Structural Technology in Architecture," Proceedings of the American Society of Engineering Educators Conference, Pittsburgh, PA, 2008.

8. Keeney-Kennicutt, W., Gunersel A.B, Simpson, N., "Overcoming Student Resistance to a Teaching Innovation," International Journal for the Scholarship of Teaching and Learning, Vol. 2, No. 1, 2008, http://www.georgiasouthern.edu/ijsotl, ISSN 1931-4744 (C) Georgia Southern University

9. ACI, Building Code Requirements for Structural Concrete and Commentary (ACI 318/318R-02), American Concrete Institute, Farmington Hills, 2002. 